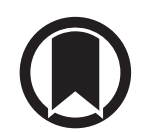

CrossMark

\title{
A systematic review of comorbidities and outcomes of adult patients with pleural infection
}

\author{
Tamsin N. Cargill (10) ${ }^{1,4}$, Maged Hassan (10), ${ }^{1,4}$ John P. Corcoran (102), \\ Elinor Harriss ${ }^{3}$, Rachelle Asciak', Rachel M. Mercer ${ }^{1}$, David J. McCracken ${ }^{1}$, \\ Eihab O. Bedawi ${ }^{1}$ and Najib M. Rahman ${ }^{1}$
}

\begin{abstract}
Affiliations: ${ }^{1}$ Oxford Centre for Respiratory Medicine, Oxford University Hospitals NHS Trust, Oxford, UK. ${ }^{2}$ Interventional Pulmonology Service, Respiratory Medicine Dept, University Hospitals Plymouth, Plymouth, UK. ${ }^{3}$ Bodleian Health Care Libraries, University of Oxford, Oxford, UK. ${ }^{4}$ Joint first authors.
\end{abstract}

Correspondence: Maged Hassan, Oxford Centre for Respiratory Medicine, Churchill Hospital, Old Road, Oxford, OX3 7LE, UK. E-mail: magedhmfagmail.com

@ERSpublications

In pleural infection, patients from higher-income countries tend to be older with more comorbidities and are more likely to be referred for fibrinolytic treatment in comparison to patients from lowerincome countries http://bit.ly/2K2M5HL

Cite this article as: Cargill TN, Hassan M, Corcoran JP, et al. A systematic review of comorbidities and outcomes of adult patients with pleural infection. Eur Respir J 2019; 54: 1900541 [https://doi.org/ 10.1183/13993003.00541-2019].

\section{ABSTRACT}

Background: Pleural infection remains an important cause of mortality. This study aimed to investigate worldwide patterns of pre-existing comorbidities and clinical outcomes of patients with pleural infection. Methods: Studies reporting on adults with pleural infection between 2000 and 2017 were identified from a search of Embase and MEDLINE. Articles reporting exclusively on tuberculous, fungal or postpneumonectomy infection were excluded. Two reviewers assessed 20980 records for eligibility.

Results: 211 studies met the inclusion criteria. 134 articles (227898 patients, mean age 52.8 years) reported comorbidity and/or outcome data. The majority of studies were retrospective observational cohorts $(\mathrm{n}=104,78 \%)$ and the most common region of reporting was East Asia ( $\mathrm{n}=33,24 \%)$ followed by North America ( $\mathrm{n}=27,20 \%) .85$ articles (50756 patients) reported comorbidity. The median (interquartile range (IQR)) percentage prevalence of any comorbidity was $72 \%$ (58-83\%), with respiratory illness $(20 \%$, 16-32\%) and cardiac illness (19\%, 15-27\%) most commonly reported. 125 papers (192298 patients) reported outcome data. The median (IQR) length of stay was 19 days (13-27 days) and median in-hospital or 30 -day mortality was $4 \%$ (IQR $1-11 \%)$. In regions with high-income economies $(\mathrm{n}=100,74 \%)$ patients were older (mean 56.5 versus 42.5 years, $\mathrm{p}<0.0001$ ), but there were no significant differences in prevalence of pre-existing comorbidity nor in length of hospital stay or mortality.

Conclusion: Patients with pleural infection have high levels of comorbidity and long hospital stays. Most reported data are from high-income economy settings. Data from lower-income regions is needed to better understand regional trends and enable optimal resource provision going forward.

This article has supplementary material available from erj.ersjournals.com

This systematic review is registered at www.crd.york.ac.uk/prospero with registration number CRD42017076418.

Data available from the Dryad Digital Repository: https://doi.org/10.5061/dryad.5d3s2vg

Received: 18 March 2019 | Accepted after revision: 19 July 2019

Copyright $\odot$ ERS 2019. This article is open access and distributed under the terms of the Creative Commons Attribution Licence 4.0. 


\section{Introduction}

Infection of the pleural space causes serious morbidity and is often life threatening [1]. Despite advances in management, 30-day mortality remains high, reported at between $9 \%$ and $10.5 \%$ in a recent Danish cohort [2]. This is especially true among older patients, in whom 30-day mortality has been reported at $20.2 \%$ in patients aged $>80$ years $[2-4]$.

Pleural infection is common, with $>30000$ diagnoses in the years 2000-2011 in the largest and most recent population-based cohort in Taiwan [5]. In recent years, incidence rates have been trending upwards [2, 3, $6]$, and coupled with advancing therapeutic techniques, the management of pleural infection represents a growing resource strain, with reported median length of hospital stay in a Canadian study averaging nearly 22 days [6]. The use of intrapleural fibrinolytics [7] as well as the improved safety profile for endoscopic thoracic surgery increased the average cost of hospitalisation in a Taiwan-based study to reach USD 4400 per admission in 2008, an increase of $>60 \%$ over the preceding 12 years of the study [4].

The underlying drivers of the rise of pleural infection cases are not fully established. Possible mechanisms include the rise of multimorbidity in ageing populations, as well as immunosuppressive states such as HIV, predisposing individuals to the condition. This is supported by data from large population-based cohorts demonstrating that incidence is skewed towards older persons and is rising more quickly in this group $[2,6]$. Furthermore, rates of comorbidity in pleural infection have been reported as being as high as $74 \%[2,5]$, and patients with increased pre-existing comorbidity have higher mortality rates $(20.6 \%$ if Charlton comorbidity score (CCS) $>2$ points, $6 \%$ if CCS 0 points) [2].

This tripartite trend of increasing incidence of pleural infection, accelerated cases among older persons and higher mortality among older and comorbid persons are consistently reported in large population-based cohorts from Canada, Taiwan, Denmark and USA [2-6]. However, these data do not necessarily represent worldwide patterns and to date no study has comprehensively reviewed the published data available. To address this, we performed a systematic review of the literature reporting the clinical characteristics and outcomes of patients with pleural infection, with a comparison between high-income and lower-income economies, of which reports from the latter are sparse. More research in low-economic settings will be essential going forward to understand regional trends and inform local resource provision.

\section{Methods}

This review was performed according to Preferred Reporting Items for Systematic Reviews and Meta-Analyses (PRISMA) guidelines and the protocol registered on the PROSPERO international prospective register of systematic reviews (CRD42017076418) [8].

\section{Search strategy}

Ovid MEDLINE and Embase were searched between 2000 and 2017 using the keywords "empyema", "pleural infection" and "pleuritis". The full search strategy is reported in detail elsewhere $[8,9]$.

\section{Data extraction}

All records were screened independently by two authors (TC and $\mathrm{MH}$ ).

The following inclusion criteria were used. 1) Population: adults (age >18 years) with bacterial pleural infection/empyema acquired in any setting (community, secondary or tertiary hospital care); 2) intervention: any intervention including conservative management with antibiotics and chest tube, intrapleural medication or any form of surgical procedure; 3) comparator: no comparator assessed; and 4) outcomes: in-hospital mortality, length of stay, escalation to surgical intervention in mixed cohort studies and any recorded comorbidity on admission.

Randomised and non-randomised controlled trials as well as observational or cross-sectional studies were included. Records with $<20$ participants were excluded due to the case selective nature of these reports.

Reports where over half of participants were aged $<18$ years or with tuberculous, fungal or post-pneumonectomy pleural infection were excluded, as the aetiology and outcome in these groups are not comparable to bacterial pleural infection in adults. Non-English language studies were included when suitable translation was available.

Data was extracted where available into a Microsoft Excel proforma. Countries of studies included in this review were classified by income as per the World Bank definition for the 2019 fiscal year [10] with gross national income (GNI) per capita in the year 2017 [11] as follows: low-income economies (GNI USD 995 per capita or less); lower-middle-income economies (GNI USD 996-3895 per capita); upper-middleincome economies (GNI USD 3896-12055 per capita); high-income economies (GNI USD 12055 or more per capita). 
Collectively in this article low, lower-middle and upper-middle economies are referred to as lower-income economies.

\section{Subgroup analysis}

Comorbidity data are reported as number and percentage of total participants in each study. Studies that specifically recruited patients with empyema and a specific disease exclusively (e.g. HIV) were excluded from the analysis of that particular comorbidity. Data were presented as prevalence of comorbidity both by affected organ/system and by specific disease.

\section{Outcome analysis}

Data on 30-day/in-hospital mortality, length of hospital stay, need for surgical intervention and intrapleural fibrinolytic therapy were collected. Studies where an entire cohort was comprised of a single intervention were excluded from analysis of that particular outcome.

Statistical analysis was performed in Prism (version 8.0; GraphPad, San Diego, CA, USA). Median values were transformed where possible to means for the age variable using the formula: mean=((lower limit+(2×median)+upper limit $)) / 4$. A t-test for parametric data or Mann-Whitney U-test for non-parametric data was performed for statistical comparison between two groups.

\section{Results}

\section{Cohort characteristics}

Of the 20980 publications returned from the initial search, 211 studies met the inclusion criteria. 134 articles (totalling 227898 patients) [2, 4-7, 12-140] reported comorbidity and/or outcome data (characteristics summarised in supplementary table $\mathrm{S} 1$ ). The remaining papers were excluded due to lack of relevant data $(n=48)$, duplicate datasets $(n=12)$, special populations predefined for exclusion in the protocol $(n=6)$, case-series of $<20$ participants $(n=10)$ or the original article was unobtainable $(n=1)$, as shown in figure 1.

The majority of studies $(\mathrm{n}=104,78 \%)$ were retrospective observational cohorts, while 17 (13\%) studies were prospective observational studies, $11(8 \%)$ were randomised controlled trials and two (2\%) were diagnostic accuracy studies. The published data were skewed towards reports from high-income economies ( $\mathrm{n}=100,74 \%$; totalling 224476 patients) with over a quarter from low, low-middle and upper-middle economies combined ( $\mathrm{n}=34,26 \%$; totalling 3422 patients, $1.5 \%)$. The most common region of reporting was East Asia ( $n=33,24 \%)$ followed by North America $(n=27,20 \%)$.

The mean age of individuals in all studies was 52.8 years (95\% CI 51.0-54.7 years). Patients in cohorts from high-income economies were significantly older than patients from lower-income economies ( 56.5 years versus 42.5 years, $\mathrm{p}<0.0001$ ).

\section{Patients with pleural infection have a high prevalence of pre-existing comorbidity}

85 articles reported comorbidity data (totalling 50756 patients, summarised in supplementary table S2). The majority of published data were from countries with high-income economies $(n=68,79 \%$; totalling 48703 patients, 96\%). Most reports were single-centre/multicentre retrospective or prospective observational cohorts $(\mathrm{n}=64,74 \%$ and $\mathrm{n}=10,12 \%$, respectively). 38 studies were cohorts including empyema treated exclusively by surgery or fibrinolysis $(n=27,31 \%$ and $n=11,13 \%$, respectively).

28 studies reported the presence of overall comorbidity levels within their dataset. The percentage prevalence of pre-existing comorbidity in patients with empyema was high (median $72 \%$, interquartile range (IQR) 58-83\%; figure $2 \mathrm{a}$ ).

Figure 2a shows the median percentage prevalence of reported comorbidity grouped by organ system affected. The percentage prevalence of smokers in patients with empyema had a median (IQR) $41 \%$ ( 30 $51 \%$; data reported in 21 studies). The median (IQR) percentage prevalence of alcohol excess in patients with empyema was $15 \%$ (8-25\%; 30 studies). The median (IQR) percentage prevalence of respiratory comorbidity in patients with empyema was $20 \%$ (16-32\%; 17 studies). This was similar to the percentage prevalence of cardiac disease $(19 \%, 15-27 \% ; 21$ studies) and higher than the percentage prevalence of malignancy (12\%, 8-23\%; 32 studies) and liver disease (5\%, 3-11\%; 33 studies).

Figure $2 \mathrm{~b}$ shows the median percentage prevalence of different comorbidities by specific disease. The median (IQR) percentage prevalence of hypertension in patients with empyema was $23 \%(17-38 \% ; 21$ studies). This was higher than the percentage prevalence of diabetes (17\%, 11-27\%; 66 studies), stroke $(13 \%, 5-20 \% ; 21$ studies), ischaemic heart disease $(11 \%, 5-16 \% ; 12$ studies), chronic obstructive pulmonary disease (11\%, 6-20\%; 40 studies) and chronic kidney disease (7\%, 5-13\%; 33 studies). The reported presence of immunosuppressive states was relatively low. The median (IQR) percentage 

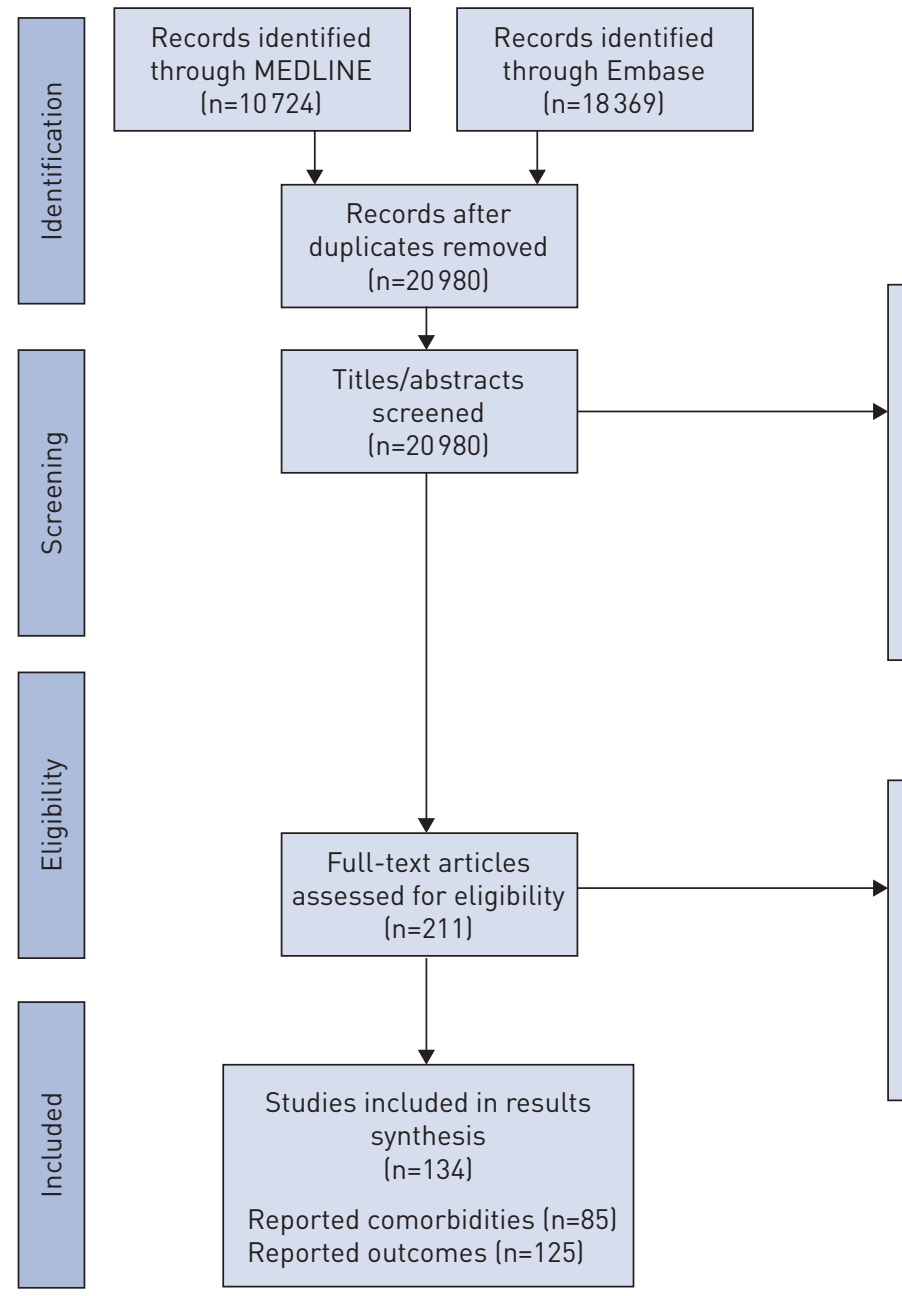

relevant: not related to pleural infection or population not of interest (paediatric, tuberculous, post-operative empyemas and spontaneous bacterial pleuritis) $(n=20324)$

Reviews/editorials ( $\mathrm{n}=67$ )

Reports of single organism/group ( $n=126)$

Case reports ( $n=163$ )

Conference abstracts $(n=25)$

Other $(n=64)$

FIGURE 1 Preferred Reporting Items for Systematic Reviews and Meta-Analyses (PRISMA) flowchart showing the identification, screening, eligibility and inclusion process.

prevalence of HIV was 4\% (1-9\%; 16 studies), steroid use 4\% (2-16\%; six studies) and recent chemotherapy in $4 \%$ (1-15\%; three studies).

Where possible, we compared comorbidity prevalence between high-income and lower-income economies. There were no significant differences between studies reporting from high-income economies compared to low-income economies in prevalence of overall pre-existing comorbidity (median $73 \%$ versus 58\%, $\mathrm{p}=0.623$ ) or diabetes mellitus (median $20 \%$ versus $14 \%, \mathrm{p}=0.0835$ ). Comparisons for other specific comorbidities were not attempted due to the paucity of data reported from lower-income economies.

\section{Patients with pleural infection have long hospital stays}

Data on outcome of pleural infection was reported in 125 papers (totalling 192298 patients). Studies reported long inpatient hospital stays (median 19 days, IQR 13-27; reported in 79 studies, totalling 180931 patients) and median (IQR) mortality in hospital or within 30 days was 4\% (1-11\%, from 105 studies totalling 179031 patients).

Prevalence of patients requiring either fibrinolytic treatment (median 31\%, IQR 17-52\%; 38 studies, 30071 patients) or surgery (median 20\%, IQR 1-32\%; 65 studies, 37330 patients) were also reported.

Figure 3 shows the differences in outcome parameters according to the income category of the country of study. There was no significant difference between studies reporting from high-income compared to lower-income economies in mean length of stay (18.7 days versus 19.7 days; figure 3a), percentage prevalence of patients receiving surgery (median $19.5 \%$ versus $20.0 \%$; figure $3 \mathrm{~b}$ ), fibrinolytic treatment (median $41 \%$ versus $24 \%, \mathrm{p}=0.1$ ) or 30 -day/in-hospital mortality (median $5 \%$ versus $4 \%$ ). 
Low-, low-middle- and upper-middle-income economies

High-income economies

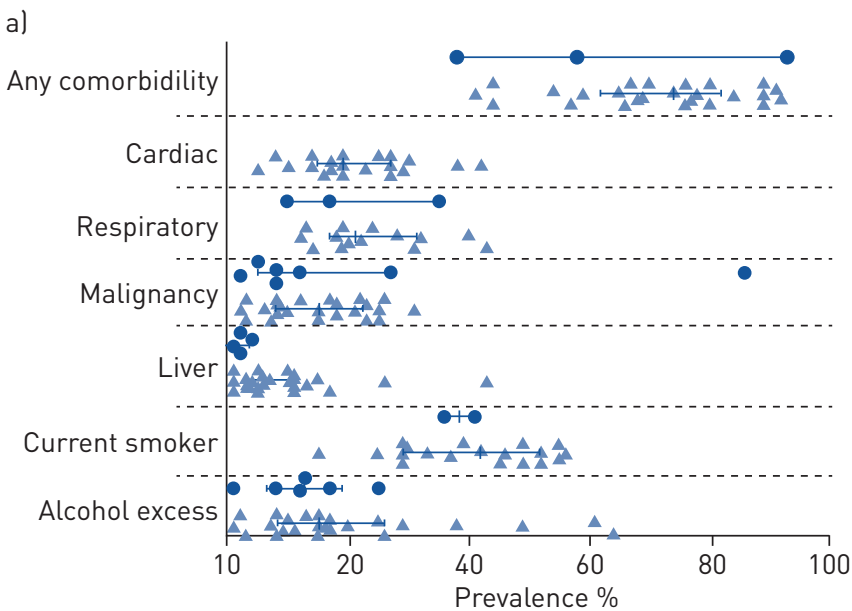

b)

b)

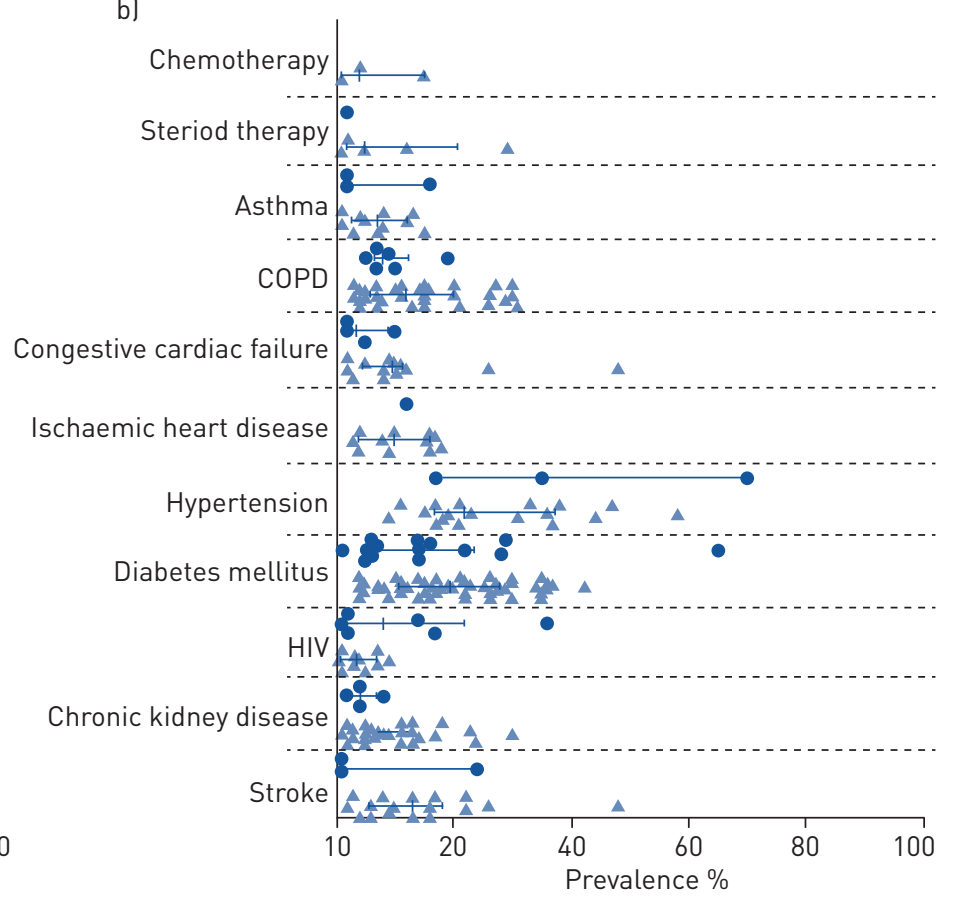

FIGURE 2 Pre-existing prevalence of comorbidity in studies of patients with pleural infection. Percentage prevalence of comorbidities in each study were extracted and data from high-income and lower-income economies were compared. a) Percentage prevalence of comorbidity, smoking, alcohol excess and disease by organ system affected; b) percentage prevalence of comorbidity by specific diseases. Data are presented as median (interquartile range). Mann-Whitney test was used to compare median prevalence of diabetes mellitus in high-income and lower-income economies. COPD: chronic obstructive pulmonary disease.

\section{Discussion}

This is the first systematic review describing the comorbidities and outcomes of studies reporting on patients with pleural infection since the turn of the 21st century. We found that the percentage prevalence of pre-existing comorbidity was high (median $72 \%$ ) with a wide range of chronic conditions affecting the major organ systems. This is consistent with large population-based studies, which have reported comorbidity prevalence of up to $74 \%$ [5] and supports the hypothesis that the rise in the incidence of pleural infection in recent years might be associated with an increasingly ageing, multi-morbid population.

Chronic respiratory and cardiovascular conditions had the highest percentage prevalence and where specific conditions were reported, hypertension, diabetes mellitus, stroke and ischaemic heart disease all had median prevalence rates between $11 \%$ and $23 \%$. As the majority of studies were from high-income settings where these conditions are endemic, this finding may seem unsurprising, and indeed, known risk factors for these diseases including smoking and alcohol excess were also reported (median $42 \%$ and $15 \%$, respectively).

When comparing studies from high-income and lower-income economies, there were no significant differences in the prevalence of pre-existing comorbidities. In high-income economies there was a higher prevalence of diabetes mellitus, but this was not significant (median $20 \%$ versus $14 \%$, $\mathrm{p}=0.08$ ). The mean age of patients in studies from high-income economies was also significantly higher than from lower-income economies (56.5 versus 42.5 years, $\mathrm{p}<0.001$ ), which probably reflects the longer life expectancy in high-income economies and the increasing prevalence of diabetes mellitus with age [141].

Evidence from large prospective population-based cohort studies will be required to investigate whether there is a causative link between the rise in chronic noncommunicable conditions such as diabetes mellitus and the increased incidence in pleural infection and whether there are true differences between high-income and lower-income economies.

Immunosuppressive states acquired through diseases such as HIV or iatrogenically induced by steroids, immunomodulatory and chemotherapeutic agents can be associated with pleural infection [48, 69]. We found a relatively low prevalence of these conditions among studies of patients with pleural infection; however, this is probably an underestimation as only a small number of studies collected these data. Studies from lower-income economies reported higher levels of HIV compared to high-income economies 

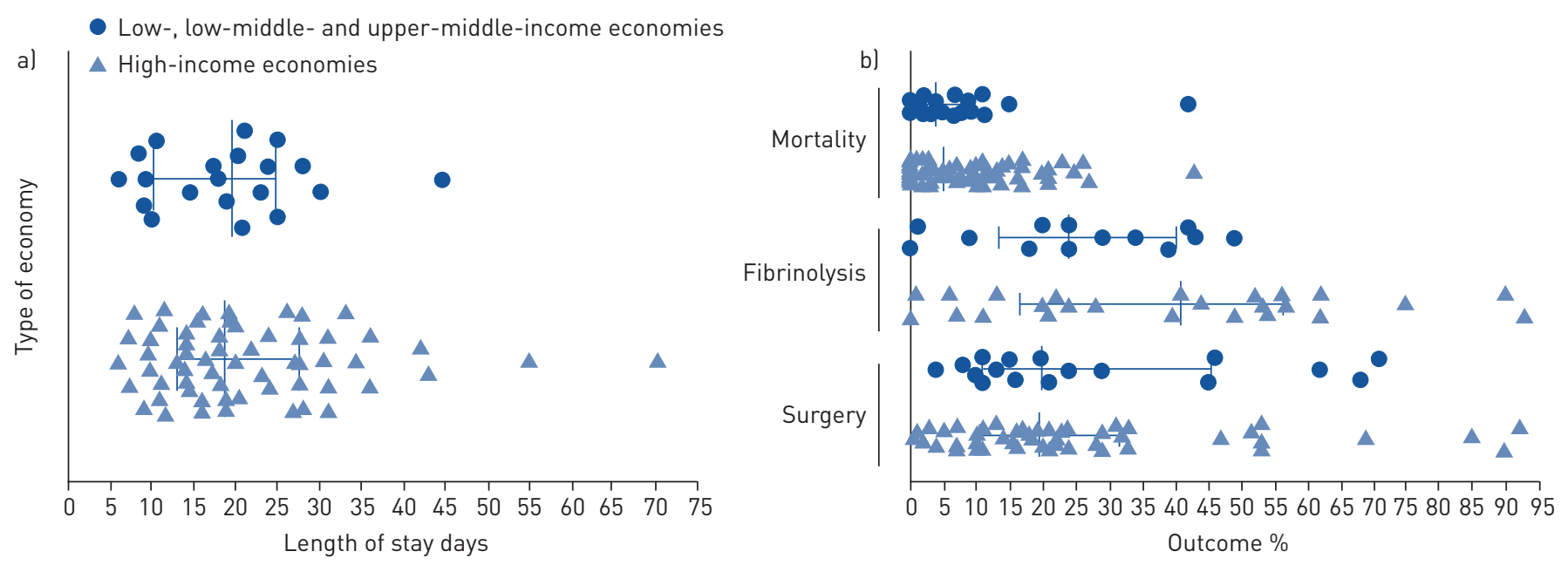

FIGURE 3 Prevalence of outcomes in studies of patients with pleural infection. Percentage prevalence of outcomes in each study were extracted and data from high-income and lower-income economies were compared. a) Mean length of hospital stay; b) percentage prevalence of mortality, patients requiring fibrinolysis and patients requiring surgical treatment. Data are presented as median (interquartile range).

(median 14\% versus 4\%), in keeping with current HIV trends, but this was not statistically significant [142]. Future studies should focus on the routine collection of these data to better understand the risk, pathogenesis and outcomes of pleural infection in these specific groups where the microbiological milieu and immune response are likely to differ from those in immunocompetent persons.

When analysing outcomes of pleural infection, we confirmed that patients have long hospital stays (median 19 days), comparable to previously reported length-of-stay data [143, 144] This supports the premise that pleural infection is an important use of healthcare resources.

We found a median in-hospital/30-day mortality of $4 \%$, which is lower than has been previously reported. The British Thoracic Society guidelines quote mortality at $20 \%$ [145], based on data from a large prospective UK cohort of patients reported in 1996 with pleural infection with an $18 \%$ mortality rate at 6 months [143] and the MIST-1 (Multicentre Intrapleural Sepsis Trial) cohort in which 12\% had died by 1 year [146]. A recent outcome study of pleural infection of $>600$ patients from Australia found 1-year mortality of $32.4 \%$ in patients with community-acquired pleural infection [147]. We recorded 30-day or in-hospital mortality rather than 3,6 or 12 months, as this was most commonly reported in the studies we analysed. Our finding of a median $4 \%$ in-hospital mortality is consistent with a prospective single centre study of pleural infection reported in 1999 , where in-hospital deaths were $4.7 \%$, rising to $14 \%$ mortality within 400 days of chest tube insertion [144]. However, in the largest, most recently published population-based cohort study of pleural infection cases in Denmark, overall unadjusted 30-day mortality was reported at between $9 \%$ and $10.5 \%$ [2]

One explanation for this is that our dataset comprises observational studies with low numbers of participants and significant risk of bias. There was a weakly positive correlation between the percentage mortality reported and number of participants $(\mathrm{r}=0.2, \mathrm{p}=0.05)$ (supplementary figure S1a). Studies with $<300$ participants had a lower median mortality than studies with $>300$ participants (4\% versus $9 \%$, $\mathrm{p}=0.072$ ) (supplementary figure $\mathrm{S} 1 \mathrm{~b}$ ) and reported a wider range of mortality estimates. There was no association between numbers of participants and age or year of publication, but as expected there is an association between mortality and age in line with previous data ( $\mathrm{r}=0.35, \mathrm{p}=0.0007$; data not shown). We were not able to investigate whether there was an association between comorbidity and outcome as the data were not reported in such a way in the original studies.

Studies with more participants are less susceptible to inclusion bias, as data are obtained from databases using International Classification of Diseases (ICD)-10 codes assigned at hospital discharge rather than locally curated cohorts. These larger studies therefore likely provide more reliable mortality estimates than our combined unadjusted estimate, and this is a weakness of our approach. Overall our analysis supports the seriousness of pleural infection, but probably underestimates the true mortality prevalence.

Despite a significant difference in mean age of patients in studies from high- and lower-income economies, the length of hospital stay, percentage of patients requiring surgery and 30-day/in-hospital mortality were similar between groups. Studies from higher-income economies reported a trend towards increased use of fibrinolytics (median $41 \%$ versus $24 \%$ ), which offers an option for symptomatic drainage 
of loculated pleural effusions in patients who are not suitable for surgery. This is consistent with a trend towards the increasing use of fibrinolytics over time in one high-income-based cohort [4]. However, prospective randomised trials have failed to show a mortality benefit from fibrinolytic treatment, and further studies are needed to explore this area of practice $[7,86]$.

This study describes the results of 134 articles reporting data from $>200000$ patients, and thus is the most comprehensive work to date examining the comorbidities and outcomes of patients with pleural infection worldwide. However, the findings may not be generalisable to all settings or fully representative of real-world trends, as the majority of studies are relatively small retrospective observational cohorts from secondary care institutions in high-income settings. Mixed cohorts were included in the analysis to maximise inclusion, and therefore some of the results will reflect patient populations with a proportion of tuberculosis, post-surgical and childhood empyema, which differ in aetiology and outcome to adult bacterial pleural infection.

In conclusion, this study confirms that pleural infection remains an important disease. Patients have a high prevalence of pre-existing comorbidity and are older in high-income economies. Importantly this study highlights the paucity of data on pleural infection from lower-income economies and calls for large prospective registries at the population level in these settings to better understand regional trends in pleural infection and to enable optimal resource provision.

Author contributions: M. Hassan, J.P. Corcoran and N.M. Rahman conceptualised and planned the study. E. Harriss conducted the literature review. T.N. Cargill and M. Hassan screened abstracts for inclusion. T.N. Cargill extracted and analysed the data and prepared the manuscript. D.J. McCracken and N.M. Rahman critically revised the first draft. All authors reviewed the final manuscript prior to submission.

Support statement: T.N. Cargill is funded as an Academic Clinical Fellow by the National Institute of Health Research and by a Wellcome Trust PhD Training Fellowship for Clinicians (grant number 211042/Z/18/Z). M. Hassan is a recipient of the European Respiratory Society Long Term Research Fellowship (ERS 2016 7333).

Conflict of interest: None declared.

\section{References}

1 Bedawi EO, Hassan M, Rahman NM. Recent developments in the management of pleural infection: a comprehensive review. Clin Respir J 2018; 12: 2309-2320.

2 Søgaard M, Nielsen RB, Nørgaard M, et al. Incidence, length of stay, and prognosis of hospitalized patients with pleural empyema: a 15-year Danish nationwide cohort study. Chest 2014; 145: 189-192.

3 Bender JM, Ampofo K, Sheng X, et al. Parapneumonic empyema deaths during past century, Utah. Emerging Infect Dis 2009; 15: 44-48.

4 Shen H-N, Lu C-L, Li C-Y. Epidemiology of pleural infections in Taiwan from 1997 through 2008: pleural infections in Taiwan. Respirology 2012; 17: 1086-1093.

$5 \mathrm{Wu} \mathrm{C}-\mathrm{Y}, \mathrm{Su} \mathrm{T}-\mathrm{W}$, Huang K-Y, et al. Pleural empyema and aortic aneurysm: a retrospective national population-based cohort study. Medicine 2015; 94: e2142.

6 Finley C, Clifton J, Fitzgerald JM, et al. Empyema: an increasing concern in Canada. Can Respir J 2008; 15: 85-89.

7 Rahman NM, Maskell NA, West A, et al. Intrapleural use of tissue plasminogen activator and DNase in pleural infection. N Engl J Med 2011; 365: 518-526.

8 Fayed M, Cargill T, Corcoran JP, et al. Patterns of Microbiology of Pleural Infection. 2017. www.crd.york.ac.uk/ PROSPERO/display_record.php?ID=CRD42017076418 Date last updated: July 15, 2019.

9 Hassan M, Cargill T, Harriss E, et al. The microbiology of pleural infection in adults: a systematic review. Eur Respir J 2019; 54: 1900542.

10 World Bank. World Bank Classification of Countries by Income 2019 definition. https://datahelpdesk.worldbank. org/knowledgebase/articles/906519 Date last accessed: Jan 16, 2019.

11 World Bank. World Bank Atlas Method. https://datahelpdesk.worldbank.org/knowledgebase/articles/378832-whatis-the-world-bank-atlas-method Date last accessed: Jan 16, 2019.

12 Abu-Daff S, Maziak DE, Alshehab D, et al. Intrapleural fibrinolytic therapy (IPFT) in loculated pleural effusions analysis of predictors for failure of therapy and bleeding: a cohort study. BMJ Open 2013; 3: e001887.

13 Ahmed RA, Marrie TJ, Huang JQ. Thoracic empyema in patients with community-acquired pneumonia. Am J Med 2006; 119: 877-883.

14 Ahmed S, Azam H, Basheer I. Is open decortication superior to fibrinolytic therapy as a first line treatment in the management of pleural empyema? Pak J Med Sci 2016; 32: 329-332.

15 Akhan O, Ozkan O, Akinci D, et al. Image-guided catheter drainage of infected pleural effusions. Diagn Interv Radiol 2007; 13: 204-209.

16 Alegre J, Jufresa J, Segura R, et al. Pleural-fluid myeloperoxidase in complicated and noncomplicated parapneumonic pleural effusions. Eur Respir J 2002; 19: 320-325.

17 Alemán C, Porcel JM, Alegre J, et al. Intrapleural fibrinolysis with urokinase versus alteplase in complicated parapneumonic pleural effusions and empyemas: a prospective randomized study. Lung 2015; 193: 993-1000.

18 Andrade-Alegre R, Garisto JD, Zebede S. Open thoracotomy and decortication for chronic empyema. Clinics 2008; 63: 789-793.

19 Anstadt MP, Guill CK, Ferguson ER, et al. Surgical versus nonsurgical treatment of empyema thoracis: an outcomes analysis. Am J Med Sci 2003; 326: 9-14. 
Asai N, Suematsu H, Hagihara M, et al. The etiology and bacteriology of healthcare-associated empyema are quite different from those of community-acquired empyema. J Infect Chemother 2017; 23: 661-667.

Baek JH, Lee YU, Lee SS, et al. Early aggressive surgical treatment of multiloculated empyema. Korean J Thorac Cardiovasc Surg 2017; 50: 202-206.

Bagheri R, Haghi SZ, Dalouee MN, et al. Effect of decortication and pleurectomy in chronic empyema patients. Asian Cardiovasc Thorac Ann 2016; 24: 245-249.

Bagheri R, Tavassoli A, Haghi SZ, et al. The role of thoracoscopic debridement in the treatment of parapneumonic empyema. Asian Cardiovasc Thorac Ann 2013; 21: 443-446.

Banga A, Khilnani GC, Sharma SK, et al. A study of empyema thoracis and role of intrapleural streptokinase in its management. BMC Infect Dis 2004; 4: 19.

Bar I, Stav D, Fink G, et al. Thoracic empyema in high-risk patients: conservative management or surgery? Asian Cardiovasc Thorac Ann 2010; 18: 337-343.

Barmparas G, DuBose J, Teixeira PGR, et al. Risk factors for empyema after diaphragmatic injury: results of a National Trauma Databank analysis. J Trauma 2009; 66: 1672-1676.

Barthwal MS, Deoskar RB, Rajan KE, et al. Intrapleural streptokinase in complicated parapneumonic effusions and empyema. Indian J Chest Dis Allied Sci 2004; 46: 257-261.

Bilgin M, Akcali Y, Oguzkaya F. Benefits of early aggressive management of empyema thoracis. ANZ J Surg 2006; 76: $120-122$.

Birkenkamp K, O’Horo JC, Kashyap R, et al. Empyema management: a cohort study evaluating antimicrobial therapy. J Infect 2016; 72: 537-543.

Bongiolatti S, Voltolini L, Borgianni S, et al. Uniportal thoracoscopic decortication for pleural empyema and the role of ultrasonographic preoperative staging. Interact Cardiovasc Thorac Surg 2017; 24: 560-566.

Bouros D, Antoniou KM, Chalkiadakis G, et al. The role of video-assisted thoracoscopic surgery in the treatment of parapneumonic empyema after the failure of fibrinolytics. Surg Endosc 2002; 16: 151-154.

Boyanova L, Djambazov V, Gergova G, et al. Anaerobic microbiology in 198 cases of pleural empyema: a Bulgarian study. Anaerobe 2004; 10: 261-267.

Brutsche MH, Tassi G-F, Györik S, et al. Treatment of sonographically stratified multiloculated thoracic empyema by medical thoracoscopy. Chest 2005; 128: 3303-3309.

Casali C, Storelli ES, Di Prima E, et al. Long-term functional results after surgical treatment of parapneumonic thoracic empyema. Interact Cardiovasc Thorac Surg 2009; 9: 74-78.

Caviezel C, Schuetz P, Gerdes S, et al. Procalcitonin as preoperative marker for surgery in advanced parapneumonic empyema. J Thorac Dis 2017; 9: 734-741.

Chalmers JD, Singanayagam A, Murray MP, et al. Risk factors for complicated parapneumonic effusion and empyema on presentation to hospital with community-acquired pneumonia. Thorax 2009; 64: 592-597.

Chan DTL, Sihoe ADL, Chan S, et al. Surgical treatment for empyema thoracis: is video-assisted thoracic surgery "better" than thoracotomy? Ann Thorac Surg 2007; 84: 225-231.

Chen $\mathrm{C}-\mathrm{H}$, Hsu $\mathrm{W}-\mathrm{H}$. Ultrasound imaging to predict the prognosis of small-bore chest tube treatment for empyema and complicated parapneumonic effusion. J Med Ultrasound 2013; 21: 176-178.

Chen $\mathrm{C}-\mathrm{H}$, Chen W, Chen $\mathrm{H}-\mathrm{J}$, et al. Transthoracic ultrasonography in predicting the outcome of small-bore catheter drainage in empyemas or complicated parapneumonic effusions. Ultrasound Med Biol 2009; 35: $1468-1474$

Chen $\mathrm{C}-\mathrm{H}$, Hsu W-H, Chen $\mathrm{H}-\mathrm{J}$, et al Different bacteriology and prognosis of thoracic empyemas between patients with chronic and end-stage renal disease. Chest 2007; 132: 532-539.

Chen KY, Hsueh PR, Liaw YS, et al. A 10-year experience with bacteriology of acute thoracic empyema: emphasis on Klebsiella pneumoniae in patients with diabetes mellitus. Chest 2000; 117: 1685-1689.

Chen K-C, Chen H-Y, Lin J-W, et al. Acute thoracic empyema: clinical characteristics and outcome analysis of video-assisted thoracoscopic surgery. J Formos Med Assoc 2014; 113: 210-218.

Cheng G, Vintch JRE. A retrospective analysis of the management of parapneumonic empyemas in a county teaching facility from 1992 to 2004. Chest 2005; 128: 3284-3290.

Chu MW, Dewar LR, Burgess JJ, et al. Empyema thoracis: lack of awareness results in a prolonged clinical course. Can J Surg 2001; 44: 284-288.

Davoodabadi A, Sadr F, Razi E, et al. Complicated parapneumonic effusion: etiology and results of lung decortication. Acta Medica Iranica 2008; 46: 291-294.

de Souza A, Offner PJ, Moore EE, et al. Optimal management of complicated empyema. Am J Surg 2000; 180: 507-511.

Desai G, Amadi W. Three years' experience of empyema thoracis in association with HIV infection. Trop Doct 2001; 31: 106-107.

Diacon AH, Theron J, Schuurmans MM, et al. Intrapleural streptokinase for empyema and complicated parapneumonic effusions. Am J Respir Crit Care Med 2004; 170: 49-53.

El Solh AA, Alhajjhasan A, Ramadan FH, et al. A comparative study of community- and nursing home-acquired empyema thoracis. J Am Geriatr Soc 2007; 55: 1847-1852.

Eren S, Esme H, Sehitogullari A, et al. The risk factors and management of posttraumatic empyema in trauma patients. Injury 2008; 39: 44-49.

Farjah F, Symons RG, Krishnadasan B, et al. Management of pleural space infections: a population-based analysis. J Thorac Cardiovasc Surg 2007; 133: 346-351.

of pleural infections in adults. Respir Med 2008; 102: 1694-1700.

Gokce M, Okur E, Baysungur V, et al. Lung decortication for chronic empyaema: effects on pulmonary function and thoracic asymmetry in the late period. Eur J Cardiothorac Surg 2009; 36: 754-758.

Grijalva CG, Zhu Y, Nuorti JP, et al. Emergence of parapneumonic empyema in the USA. Thorax 2011; 66: 663-668.

Hagos G, Esayas R, G/Selassie K. Open window thoracostomy, still an option in the management of chronic empyema: experience from Ayder referral hospital. Ethiop Med J 2016; 54: 17-20. 
Hajjar WM, Ahmed I, Al-Nassar SA, et al. Video-assisted thoracoscopic decortication for the management of late stage pleural empyema, is it feasible? Ann Thorac Med 2016; 11: 71-78.

Hardavella G, Papakonstantinou NA, Karampinis I, et al. Hippocrates quoted "if an empyema does not rupture, death will occur": is medical thoracoscopy able to make it rupture safely? J Bronchology Interv Pulmonol 2017; 24: 15-20.

Heimes J, Copeland H, Lulla A, et al. The use of thrombolytics in the management of complex pleural fluid collections. J Thorac Dis 2017; 9: 1310-1316.

Herrera-Kiengelher L, Báez-Saldaña R, Salas-Hernández J, et al. Frequency of adverse events and mortality in patients with pleural empyema in a public referral hospital in Mexico City. Int J Tuberc Lung Dis 2010; 14: $1187-1192$.

Hooper CE, Edey AJ, Wallis A, et al. Pleural irrigation trial (PIT): a randomised controlled trial of pleural irrigation with normal saline versus standard care in patients with pleural infection. Eur Respir J 2015; 46: 456-463.

Hoth JJ, Burch PT, Bullock TK, et al. Pathogenesis of posttraumatic empyema: the impact of pneumonia on pleural space infections. Surg Infect 2003; 4: 29-35.

Hsiao C-H, Chen K-C, Chen J-S. Modified single-port non-intubated video-assisted thoracoscopic decortication in high-risk parapneumonic empyema patients. Surg Endosc 2017; 31: 1719-1727.

Hsieh M-J, Liu Y-H, Chao Y-K, et al. Risk factors in surgical management of thoracic empyema in elderly patients. ANZ J Surg 2008; 78: 445-448.

Huang $\mathrm{H}-\mathrm{C}$, Chen $\mathrm{H}-\mathrm{C}$, Fang $\mathrm{H}-\mathrm{Y}$, et al. Lung abscess predicts the surgical outcome in patients with pleural empyema. J Cardiothorac Surg 2010; 5: 88.

Jiménez D, Díaz G, García-Rull S, et al. Routine use of pleural fluid cultures. Are they indicated? Limited yield, minimal impact on treatment decisions. Respir Med 2006; 100: 2048-2052.

Kearney SE, Davies CW, Davies RJ, et al. Computed tomography and ultrasound in parapneumonic effusions and empyema. Clin Radiol 2000; 55: 542-547.

Keeling AN, Leong S, Logan PM, et al. Empyema and effusion: outcome of image-guided small-bore catheter drainage. Cardiovasc Intervent Radiol 2008; 31: 135-141.

Khwaja S, Rosenbaum DH, Paul MC, et al. Surgical treatment of thoracic empyema in HIV-infected patients: severity and treatment modality is associated with CD4 count status. Chest 2005; 128: 246-249.

Kim B-Y, Oh B-S, Jang W-C, et al. Video-assisted thoracoscopic decortication for management of postpneumonic pleural empyema. Am J Surg 2004; 188: 321-324.

Kim J, Park JS, Cho Y-J, et al. Predictors of prolonged stay in patients with community-acquired pneumonia and complicated parapneumonic effusion. Respirology 2016; 21: 164-171.

Kim S-K, Kang CU, Song SH, et al. Factors predictive of the failure of medical treatment in patients with pleural infection. Korean J Intern Med 2014; 29: 603-612.

Koma Y, Inoue S, Oda N, et al. Clinical characteristics and outcomes of patients with community-acquired, health-care-associated and hospital-acquired empyema. Clin Respir J 2017; 11: 781-788.

Kundu S, Mitra S, Mukherjee S, et al. Adult thoracic empyema: a comparative analysis of tuberculous and nontuberculous etiology in 75 patients. Lung India 2010; 27: 196-201.

Lardinois D, Gock M, Pezzetta E, et al. Delayed referral and Gram-negative organisms increase the conversion thoracotomy rate in patients undergoing video-assisted thoracoscopic surgery for empyema. Ann Thorac Surg 2005; 79: 1851-1856.

Lee H, Park S, Shin H, et al. Assessment of the usefulness of video-assisted thoracoscopic surgery in patients with non-tuberculous thoracic empyema. J Thorac Dis 2015; 7: 394-399.

Levinson GM, Pennington DW. Intrapleural fibrinolytics combined with image-guided chest tube drainage for pleural infection. Mayo Clin Proc 2007; 82: 407-413.

Li B, Liu C, Li Y, et al. Computed tomography-guided catheter drainage with urokinase and ozone in management of empyema. World J Radiol 2017; 9: 212-216.

Lin M-C, Chen Y-C, Wu J-T, et al. Diagnostic and prognostic values of pleural fluid procalcitonin in parapneumonic pleural effusions. Chest 2009; 136: 205-211.

Lin Y-C, Tu C-Y, Chen W, et al. An urgent problem of aerobic Gram-negative pathogen infection in complicated parapneumonic effusions or empyemas. Intern Med 2007; 46: 1173-1178.

Luh S-P, Chou M-C, Wang L-S, et al. Video-assisted thoracoscopic surgery in the treatment of complicated parapneumonic effusions or empyemas: outcome of 234 patients. Chest 2005; 127: 1427-1432.

Majid A, Kheir F, Folch A, et al. Concurrent intrapleural instillation of tissue plasminogen activator and DNase for pleural infection. A single-center experience. Ann Am Thorac Soc 2016; 13: 1512-1518.

Malhotra P, Aggarwal AN, Agarwal R, et al. Clinical characteristics and outcomes of empyema thoracis in 117 patients: a comparative analysis of tuberculous vs. non-tuberculous aetiologies. Respir Med 2007; 101: 423-430.

Marks DJB, Fisk MD, Koo CY, et al. Thoracic empyema: a 12-year study from a UK tertiary cardiothoracic referral centre. PLoS One 2012; 7: e30074.

Marra A, Huenermann C, Ross B, et al. Management of pleural empyema with single-port video-assisted thoracoscopy. Innovations 2012; 7: 338-345.

Maskell NA, Davies CWH, Nunn AJ, et al. U.K. controlled trial of intrapleural streptokinase for pleural infection. N Engl J Med 2005; 352: 865-874.

McClune JR, Wilshire CL, Gorden JA, et al. Safety and efficacy of intrapleural tissue plasminogen activator and DNase during extended use in complicated pleural space infections. Can Respir J 2016; 2016: 9796768.

Medeiros IL, Terra RM, Choi EM, et al. Evaluation of serial C-reactive protein measurements after surgical treatment of pleural empyema. Clinics 2012; 67: 243-247.

Mehta HJ, Biswas A, Penley AM, et al. Management of intrapleural sepsis with once daily use of tissue plasminogen activator and deoxyribonuclease. Respiration 2016; 91: 101-106.

Melloni G, Carretta A, Ciriaco P, et al. Decortication for chronic parapneumonic empyema: results of a prospective study. World J Surg 2004; 28: 488-493.

Metaxas EK, Condilis N, Tzatzadakis N, et al. Therapy of the empyema thoracis. Why not thoracostoma? Ann Ital Chir 2007; 78: 307-310. 
Metin M, Yeginsu A, Sayar A, et al. Treatment of multiloculated empyema thoracis using minimally invasive methods. Singapore Med J 2010; 51: 242-246.

92 Mikkola R, Kelahaara J, Heikkinen J, et al. Poor late survival after surgical treatment of pleural empyema. World J Surg 2010; 34: 266-271.

93 Misthos P, Sepsas E, Konstantinou M, et al. Early use of intrapleural fibrinolytics in the management of postpneumonic empyema. A prospective study. Eur J Cardiothorac Surg 2005; 28: 599-603.

94 Monteiro R, Alfaro TM, Correia L, et al. Abcesso pulmonar e empiema torácico: análise retrospectiva num serviço de medicina interna [Lung abscess and thoracic empyema: retrospective analysis in an internal medicine department]. Acta Med Port 2011; 24: Suppl. 2, 229-240.

95 Muhammad MIA. Management of complicated parapneumonic effusion and empyema using different treatment modalities. Asian Cardiovasc Thorac Ann 2012; 20: 177-181.

96 Nadir A, Kaptanoglu M, Gonlugur U, et al. Empyema in adults and children: difference in surgical approaches, report of 139 cases. Acta Chir Belg 2007; 107: 187-191.

97 Nakamoto K, Takeshige M, Fujii T, et al. Electrolyzed saline irrigation for elimination of bacterial colonization in the empyema space. Surg Infect 2016; 17: 724-729.

98 Nakamura H, Taniguchi Y, Miwa K, et al. Surgical outcome of video-assisted thoracic surgery for acute thoracic empyema using pulsed lavage irrigation. Gen Thorac Cardiovasc Surg 2010; 58: 126-130.

99 Nandeesh M, Sharathchandra BJ, Thrishuli PB. ICD Versus VATS as primary treatment in fibrinopurulent stage of empyema thoracis. J Clin Diagn Res 2013; 7: 2855-2858.

100 Nielsen J, Meyer CN, Rosenlund S. Outcome and clinical characteristics in pleural empyema: a retrospective study. Scand J Infect Dis 2011; 43: 430-435.

101 O'Connor JV, Chi A, Joshi M, et al. Post-traumatic empyema: aetiology, surgery and outcome in 125 consecutive patients. Injury 2013; 44: 1153-1158.

102 Ohuchi M, Inoue S, Ozaki Y, et al. Single-trocar thoracoscopy under local anesthesia for pleural space infection. Gen Thorac Cardiovasc Surg 2014; 62: 503-510.

103 Okada M, Tsubota N, Yoshimura M, et al. Surgical treatment for chronic pleural empyema. Surg Today 2000; 30: 506-510.

104 Okiror L, Coltart C, Bille A, et al. Thoracotomy and decortication: impact of culture-positive empyema on the outcome of surgery. Eur J Cardiothorac Surg 2014; 46: 901-906.

105 Ozol D, Oktem S, Erdinc E. Complicated parapneumonic effusion and empyema thoracis: microbiologic and therapeutic aspects. Respir Med 2006; 100: 286-291.

106 Park C-K, Oh H-J, Choi H-Y, et al. Microbiological characteristics and predictive factors for mortality in pleural infection: a single-center cohort study in Korea. PLoS One 2016; 11: e0161280.

107 Pefura Yone EW, Kuaban C, Afane Ze E, et al. Caractéristiques cliniques, bactériologiques et évolutives de la pleurésie purulente non-tuberculeuse chez les patients adultes séropositifs et séronégatifs au VIH à Yaoundé, Cameroun [Clinical characteristics, microbiologic findings and outcome of non-tuberculous purulent pleural effusion in HIV-infected and non HIV-infected adult patients in Yaounde, Cameroon]. Rev Pneumol Clin 2012; 68: 225-232.

108 Petrakis IE, Kogerakis NE, Drositis IE, et al. Video-assisted thoracoscopic surgery for thoracic empyema: primarily, or after fibrinolytic therapy failure? Am J Surg 2004; 187: 471-474.

109 Petrusevska-Marinkovic S, Kondova-Topuzovska I, Milenkovic Z, et al. Clinical, laboratory and radiographic features of patients with pneumonia and parapneumonic effusions. Open Access Maced J Med Sci 2016; 4: 428-434.

110 Pilav I, Guska S, Musanovic S, et al. Surgical treatment of pleural empyema according to disease stage. Med Arh 2009; 63: 291-294.

111 Podbielski FJ, Maniar HS, Rodriguez HE, et al. Surgical strategy of complex empyema thoracis. JSLS 2000; 4: 287-290.

112 Popowicz N, Bintcliffe O, De Fonseka D, et al. Dose de-escalation of intrapleural tissue plasminogen activator therapy for pleural infection. The Alteplase Dose Assessment for Pleural Infection Therapy project. Ann Am Thorac Soc 2017; 14: 929-936.

113 Porcel JM, Pardina M, Alemán C, et al. Computed tomography scoring system for discriminating between parapneumonic effusions eventually drained and those cured only with antibiotics. Respirology 2017; 22: 1199-1204.

114 Potaris K, Mihos P, Gakidis I, et al. Video-thoracoscopic and open surgical management of thoracic empyema. Surg Infect 2007; 8: 511-517.

115 Powell LL, Allen R, Brenner M, et al. Improved patient outcome after surgical treatment for loculated empyema. Am J Surg 2000; 179: 1-6.

116 Ravaglia C, Gurioli C, Tomassetti S, et al. Is medical thoracoscopy efficient in the management of multiloculated and organized thoracic empyema? Respiration 2012; 84: 219-224.

117 Roberts JR. Minimally invasive surgery in the treatment of empyema: intraoperative decision making. Ann Thorac Surg 2003; 76: 225-230.

118 Rodríguez Suárez P, Freixinet Gilart J, Hernández Pérez JM, et al. Treatment of complicated parapneumonic pleural effusion and pleural parapneumonic empyema. Med Sci Monit 2012; 18: CR443-CR449.

119 Schweigert M, Solymosi N, Dubecz A, et al. Surgery for parapneumonic pleural empyema - what influence does the rising prevalence of multimorbidity and advanced age has on the current outcome? Surgeon 2016; 14: 69-75.

120 Shankar S, Gulati M, Kang M, et al. Image-guided percutaneous drainage of thoracic empyema: can sonography predict the outcome? Eur Radiol 2000; 10: 495-499.

121 Shin JA, Chang YS, Kim TH, et al. Surgical decortication as the first-line treatment for pleural empyema. J Thorac Cardiovasc Surg 2013; 145: 933-939.

122 Smolikov A, Smolyakov R, Riesenberg K, et al. Prevalence and clinical significance of pleural microbubbles in computed tomography of thoracic empyema. Clin Radiol 2006; 61: 513-519.

123 Solaini L, Prusciano F, Bagioni P. Video-assisted thoracic surgery in the treatment of pleural empyema. Surg Endosc 2007; 21: 280-284. 
124 Soriano T, Alegre J, Alemán C, et al. Factors influencing length of hospital stay in patients with bacterial pleural effusion. Respiration 2005; 72: 587-593.

125 Swart MJ. Profile and outcome of patients referred for thoracic empyema in Bloemfontein, South Africa. $S$ Afr Med J 2002; 92: 364-368.

126 Tantraworasin A, Thepbunchonchai A, Siwachat S, et al. Factors associated with recurrent bacterial empyema thoracis. Asian J Surg 2018; 41: 313-320.

127 Terra RM, Waisberg DR, Almeida JLJ, et al. Does videothoracoscopy improve clinical outcomes when implemented as part of a pleural empyema treatment algorithm? Clinics 2012; 67: 557-564.

128 Thommi G, Shehan JC, Robison KL, et al. A double blind randomized cross over trial comparing rate of decortication and efficacy of intrapleural instillation of alteplase $v s$ placebo in patients with empyemas and complicated parapneumonic effusions. Respir Med 2012; 106: 716-723.

129 Thommi G, Nair CK, Aronow WS, et al. Efficacy and safety of intrapleural instillation of alteplase in the management of complicated pleural effusion or empyema. Am J Ther 2007; 14: 341-345.

130 Tsai C-H, Lai Y-C, Chang S-C, et al. Video-assisted thoracoscopic surgical decortication in the elderly with thoracic empyema: five years' experience. J Chin Med Assoc 2016; 79: 25-28.

131 Tsang KY, Leung WS, Chan VL, et al. Complicated parapneumonic effusion and empyema thoracis: microbiology and predictors of adverse outcomes. Hong Kong Med J 2007; 13: 178-186.

132 Tsujimoto N, Saraya T, Light RW, et al. A simple method for differentiating complicated parapneumonic effusion/empyema from parapneumonic effusion using the split pleura sign and the amount of pleural effusion on thoracic CT. PLoS One 2015; 10: e0130141.

133 Tuncozgur B, Ustunsoy H, Sivrikoz MC, et al. Intrapleural urokinase in the management of parapneumonic empyema: a randomised controlled trial. Int J Clin Pract 2001; 55: 658-660.

134 Vaziri M, Abed O. Management of thoracic empyema: review of 112 cases. Acta Med Iran 2012; 50: 203-207.

135 White HD, White BAA, Song J, et al. Pleural infections: a 9-year review of bacteriology, case characteristics and mortality. Am J Med Sci 2013; 345: 349-354.

136 Wong D, Yap E. Pleural infection in a New Zealand centre: high incidence in Pacific people and RAPID score as a prognostic tool. Intern Med J 2016; 46: 703-709.

137 Wozniak CJ, Paull DE, Moezzi JE, et al. Choice of first intervention is related to outcomes in the management of empyema. Ann Thorac Surg 2009; 87: 1525-1530.

138 Wurnig PN, Wittmer V, Pridun NS, et al. Video-assisted thoracic surgery for pleural empyema. Ann Thorac Surg 2006; 81: 309-313

139 Yamaguchi M, Takeo S, Suemitsu R, et al. Video-assisted thoracic surgery for fibropurulent thoracic empyema: a bridge to open thoracic surgery. Ann Thorac Cardiovasc Surg 2009; 15: 368-372.

140 Porcel JM, Valencia H, Bielsa S. Manual intrapleural saline flushing plus urokinase: a potentially useful therapy for complicated parapneumonic effusions and empyemas. Lung 2017; 195: 135-138.

141 Organisation for Economic Co-Operation and Development (OECD). Health at a Glance 2017: OECD Indicators. https://doi.org/10.1787/health_glance-2017-en Date last accessed: November 6, 2019.

142 World Health Organization (WHO). Number of People (All Ages) Living with HIV Estimates by WHO Region, Global Health Observatory Data Repository. http://apps.who.int/gho/data/view.main.22100WHO?lang=en Date last accessed: January 20, 2019.

143 Ferguson AD, Prescott RJ, Selkon JB, et al. The clinical course and management of thoracic empyema. QJM 1996; 89: 285-289

144 Davies CW, Kearney SE, Gleeson FV, et al. Predictors of outcome and long-term survival in patients with pleural infection. Am J Respir Crit Care Med 1999; 160: 1682-1687.

145 Davies HE, Davies RJO, Davies CWH, et al. Management of pleural infection in adults: British Thoracic Society Pleural Disease Guideline 2010. Thorax 2010; 65: Suppl. 2, ii41-ii53.

146 Maskell NA, Lee YCG, Gleeson FV, et al. Randomized trials describing lung inflammation after pleurodesis with talc of varying particle size. Am J Respir Crit Care Med 2004; 170: 377-382.

147 Brims F, Popowicz N, Rosenstengel A, et al. Bacteriology and clinical outcomes of patients with culture-positive pleural infection in Western Australia: a 6-year analysis. Respirology 2019; 24: 171-178. 